\title{
Analysis Effect of Duct Length- Nozzle Diameter Ratio and Tip Clearance Variation on the Performance of K-Series Propeller
}

\author{
Irfan Syarif Arief ${ }^{1}$, Tony Bambang Musriyadi ${ }^{2}$, Ahmad Dwi Arta Je Mafera $^{3}$,
}

\begin{abstract}
Ducted propellers are propellers with sheath or duct that can increase thrust on the propeller and useful for directing the flow of water that will pass through the Propeller. In addition to improving thrust, ducted propellers can also increase torque compared with no duct. The basic theory of momentum for this ducted propeller operation has been used by Horn (1940). In order for the efficiency of the thrust to be of good value, the volume of water passing through the propeller should be as large as possible, with the smallest possible flow velocity. The most important components of ducted propeller are Ld / D and tip clearance. Ld / D is a coefficient comparison between the length of the casing / duct and the diameter of the duct, while the tip clearance is the distance between the tip of the propeller with an inner diameter of the duct. Both components are discussed in this study. The purpose of this research is to know the performance of propeller after given variation on $\mathrm{Ld} / \mathrm{D}$ and tip clearance. The method used for propeller analysis is Computational Fluid Dynamic (CFD). Based on simulation result, the most optimal propeller performance is ducted propeller with $\mathrm{Ld} / \mathrm{D}=\mathbf{0 . 5}$ and tip clearance $40 \mathrm{~mm}$
\end{abstract}

Keywords-CFD , Ducted Propeller, Ld/D, Tip Clearance, Kaplan

\section{INTRODUCTION}

$\mathrm{T}$ The ship is one of the many types of transportation that exist in this world. The vessel has a promising value in the future. To support the performance of the vessel required a variety of good support systems, one of which is the propulsion system. In the selection of propulsion systems must be adapted to the type of vessel and the characteristics of the required propulsion system.

Propeller is one of the equipment in the propulsion system. Propeller used as a mover on the ship, so the ship can move from one place to another place. Along with the development of technology in the present era, various innovations about propeller also experienced the development. There are various types of propellers that have been developed to achieve good thrust efficiency compared to conventional or conventional propellers. As for examples of types of propellers that have been developed so far such as, B-Series, KCA-Series. Japanese AU-Series, Gwan Series, Ducted Propeller and so forth.

One type of propeller developed in ducted type propellers in particular to maximize thrust is a type of ducted propeller. Ducted propeller is a type of propeller that has a nozzle (duct). Giving the ducts in addition to enhancing the thrust force also to direct the flow of water to the propeller, so that the volume of water passing through the propeller increases [3]. This type of propeller is often used on tugboats.

However, in the development of ducted propellers still use some kind of nozzle with the ratio of the length of

Irfan Syarif Arief, Department of Marine Engineering, Institut Teknologi Sepuluh Nopember, Surabaya 60111, Indonesia, Email : irfansya@its.ac.id

Tony Bambang Musriyadi, Department of Marine Engineering, Institut Teknologi Sepuluh Nopember, Surabaya 60111, Indonesia, Email : tobal@its.ac.id

Ahmad Dwi Arta Je Mafera, Department of Marine Engineering, Institut Teknologi Sepuluh Nopember, Surabaya 60111, Indonesia, Email : arta.mafera13@mhs.ne.its.ac.id fixed nozzle diameters for the duct. So from the problem it is necessary to analyze the influence of variation of the ratio of the length of the nozzle-diameter values to the performance of the ducted propeller, especially the KaSeries type propeller. And also need to be analyzed influence of distance (tip clearence) between propeller with duct. The analysis uses Computational Fluid Dynamic (CFD) method.

\section{LITERATURE REVIEW}

A. Nozzle

An important part of a ducted propeller is the nozzle or sheath that surrounds the propeller itself. Basically the principle of the ducted propeller itself is the application of momentum theory. The basic theory of momentum for this ducted propeller operation has been used by Horn (1940). In order for the efficiency of the thrust to be of good value, the volume of water passing through the propeller should be as large as possible, with the smallest possible flow velocity [7].

In making a duct, the most important thing is $\mathrm{L}_{\mathrm{d}}$ / D. $L_{d}$ is the length of the duct, while $D$ is the diameter of the duct itself. In addition to $\mathrm{L}_{\mathrm{d}}$, the most important thing in ducted propellers is tip clearance $\left(T_{C}\right)$. Tip clearance is the distance between the tip of the propeller with the inner diameter of the duct (D). Large tip clearance on the ducted propeller affects the efficiency and thrust force of the propeller (thrust).

B. Open Water Test

In general, the characteristics of ship propellers in open water test conditions are as represented in KT KQ - J Diagram [5]. Open Water Test is an analysis performed on the propeller in a state without the hull of a ship, in the sense that it consists only of axle and propeller which will then Flowed with fluids that have a certain speed. The equation model for ship propeller performance characteristics is as follows:

$$
\begin{aligned}
K_{T} & =\frac{T}{\rho n^{2} D^{4}} \\
K_{Q} & =\frac{Q}{\rho n^{2} D^{5}}
\end{aligned}
$$




$$
I=\frac{V_{a}}{n D}
$$

Where $K_{T}$ is Propeller thrust coefficient, $K_{Q}$ is Propeller torque coefficient, $\mathrm{J}$ is advanced propeller coefficient, $\mathrm{V}_{\mathrm{a}}$ is advanced speed, $\mathrm{D}$ is diameter of propeller, $\mathrm{n}$ is propeller speed, $\mathrm{T}$ is the thrust of propeller, $\mathrm{Q}$ is the torque of propeller and $\rho$ is fluid density.

For the efficiency of the propeller in open water is given the formula:

$$
\eta_{0}=\frac{T V_{\alpha}}{2 \pi n Q}
$$

\section{Force Drag and Force Lift}

Force Drag and Force Lift according to Popov are the stress multiplied by each area where the stress works and produces forces. While the sum of these forces must remain constant or constant in their equilibrium on an imaginary piece [6].

Another component of the intensity of the force acting in parallel to the wide area of the elementary is called the shear stress, denoted by $\tau$ (tau), so that it can be mathematically defined as follows:

$$
\tau=\lim _{A \rightarrow 0} \frac{\Delta V}{\Delta A}
$$

So from the above equation can be written mathematical formula of force drag as follows

$$
F_{\text {dra, }}=\tau \times A
$$

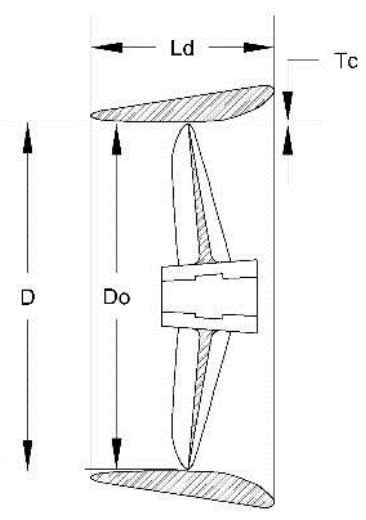

Figure. 1. Ducted Propeller Geometry

Whereas to get the mathematical formula force lift from equation above is as follows:

$$
F_{\text {lift }}=P \times A
$$

Where, $F_{\text {Drag }}$ is force drag, $F_{\text {Lift }}$ is force lift, $\tau$ is wallshear, $\mathrm{P}$ is pressure and $\mathrm{A}$ is Area.

D. Thrust and Torque

Thrust is a force that works on the propeller to push the ship, so the ship can move from one place to another. The mathematical formula of thrust can be derived from the theory of blade element momentum.

The blade element theory of momentum is a theory that combines the theory of blade elements with the theory of momentum, so the theory of blade element momentum can be used to calculate the forces acting on the propeller. So we can use the following equations to find out the forces acting on the blade:

$$
\begin{aligned}
& F_{z}=F_{L} \cos \theta-F_{D} \sin \theta \\
& F_{z}=F_{L} \sin \theta+F_{D} \cos \theta
\end{aligned}
$$

So from the equation of blade element theory momentum can be expressed equation for thrust as follows:

$$
T=F_{\text {Lift }} \cos \theta-F_{\text {Draq }} \sin \theta
$$

Where, $T$ is thrust, $F_{\text {Lift }}$ is force lift, $F_{\text {drag }}$ is force drag and $\theta$ is pitch angle.

Torque is the twisting ability given to an object (propeller), causing the object rotates on its axis. The torque can be defined by the product of the force $(\mathrm{F})$ with the moment arm, so it can be written:

$$
\tau=F \times r
$$

Where, $\tau$ is torque, $\mathrm{F}$ is force and $\mathrm{r}$ is moment arm.

So if the torque works on a blade, then based on the blade element theory the momentum equation can be defined:

$$
Q=\left(F_{\text {Lift }} \sin \theta+F_{\text {Draq }} \cos \theta\right) \times r
$$

Where, $\mathrm{Q}$ is torque, $\mathrm{F}_{\mathrm{Lift}}$ is force lift, $\mathrm{F}_{\mathrm{drag}}$ is force drag and $\theta$ is pitch angle. 

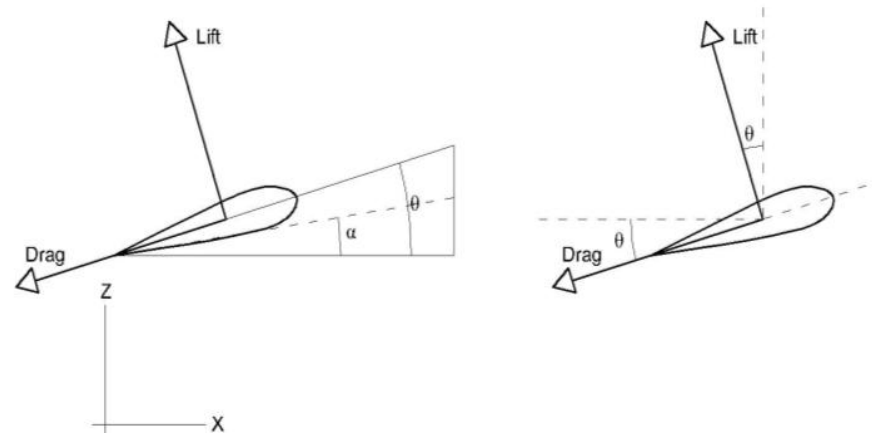

Figure. 2. Blade Element Theory

\section{METHOD}

In this research, an analysis of the performance of KaSeries propellers varied on $\mathrm{Ld} / \mathrm{D}$ ratio and tip clearance. The first step is making the model according to the problem limitation and ordinate nozzle data obtained from previous research. The model depiction is drawn with Computer Aided Design (CAD) software. Next is done meshing and simulation on propeller using Computational Fluid Dynamic (CFD) software. Data taken from simulation results in Computational Fluid Dynamic (CFD) software are pressure, wallshear and torque. These data are used to calculate the thrust, torque and efficiency. In addition to these data, the results obtained from Computational Fluid Dynamic software (CFD) is animation and image contour pressure and flow propeller model. From these results will be analyzed Kaseries performance propeller.

\section{RESULTS AND DISCUSSION}

1) Simulation Process Using Computational Fluid
Dynamic (CFD) software

Computational Fluid Dynamic (CFD) is a numerical analysis method used to solve fluid dynamics problems. Since the great advances in computer performance, the Computational Fluid Dynamic (CFD) method is used to solve the Reynolds Averaged Navier-Stokes (RANS) equations that have been applied to different types of propellers.

There are several processes performed in the Computational Fluid Dynamic (CFD) method. As for the process in Computational Fluid Dynamic (CFD) there are 3 parts:

- Pre Processor

PreProcessor is the initial stage in Computational Fluid Dynamic (CFD) which is the stage of data input that includes the determination of domain and boundary condition. At this stage meshing is also done, where the analyzed object is divided in the number of specific grids.

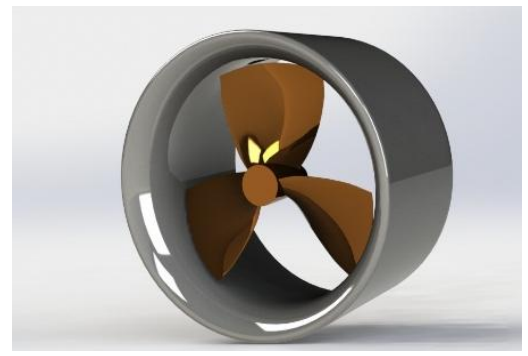

(a)

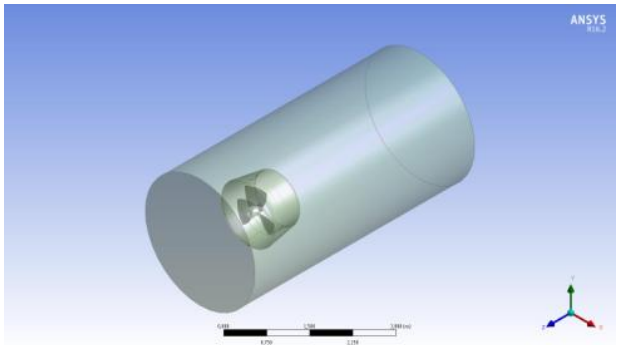

(b)

Figure. 3. (a) Propeller Model , (b) propeller with boundary

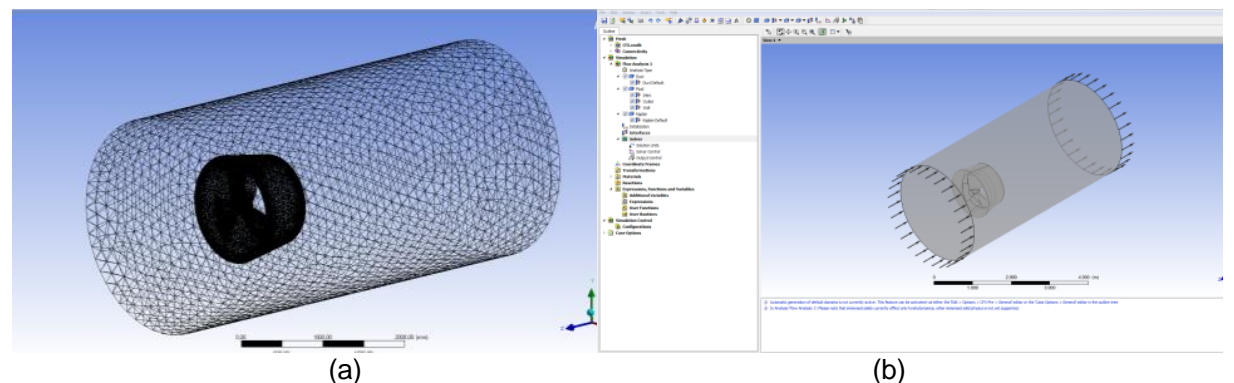

Figure. 3. (a) meshing, (b) boundary condition setup 


\section{- $\quad$ Processor}

The next stage is the stage processor, where at this stage is done data calculation process that has been entered using the related equation iteratively until the results obtained can reach the smallest error value.

- Post Processor

The last stage is the post processor stage, the results of the calculations at the stage of the processor will be displayed in pictures, graphics and animations.

2) Data Processing

In accordance with the purpose of this study, which is analyzing the performance of ducted Ka-series propellers, then performed calculations to determine the performance of the propeller of the simulation results data that has been done. The data of the simulation result are data: area, pressure, wallshear and torque. From the data that has been obtained from the simulation, performed data processing to determine the performance of the propeller. Here is the calculation to know the performance of propeller:

a. Determine the force lift value

In accordance with equation (7), the Force Lift or lift is obtained from the Pressure and Area values obtained from the simulated results in CFX-post. The value of pressure taken is a value parallel to the axis rotate propeller or $\mathrm{Z}$ axis. The pressure value is taken on the face and back. In addition to the pressure value taken, the face and back are also taken on the face and back also taken the value of area on the face and back is calculate the value of force lift. The value of force lift is resultant from force lift value on face and back, so get the value of force lift which will then be processed into thrust.

b. Determine the force drag value

The force drag value is obtained from the wallshear and area values, the values obtained from the simulation results are read by the function calculator in the CFX-post. The wallshear value taken is a value perpendicular to the propeller's axis or $\mathrm{X}$ axis. The wallshear value is taken on the face and back. Besides the value of pressure taken, the face and back are also taken the value of area on the face and back are used to calculate the lift force value. The force drag value is the resultant of the force drag value on the face and back, so get the value of force drag which will then be processed into thrust.

c. Determine the thrust value

In accordance with the problem limitation, the $\mathrm{P} / \mathrm{D}$ propeller value is 0.6. Then get the pitch angle of:

$$
\begin{aligned}
& \theta=\tan ^{-1} \frac{\frac{F}{D}}{2 \pi r} \\
& \theta=\tan ^{-1} \frac{P / D}{0.7 \pi}\left(\theta \text { calculated on } 0.7^{r} / R\right) \\
& \theta=\tan ^{-1} \frac{0.6}{0.7 \pi} \\
& \theta=15.276^{\circ}
\end{aligned}
$$

So that after the obtained force lift and force drag, according to equation (10) and the pitch angle value obtained, then get the thrust value to be displayed in a graphic.

d. Determine the torque value

The torque value is obtained from the resultant torque value taken from the simulation result read by the function calculator in CFX-post. The torque value taken is a value perpendicular to the propeller's axis or $\mathrm{X}$ axis. The torque value is taken on the face and back. The force drag value is the resultant of the force drag value on the face and back, then get the torque value to be displayed in a graphic.

e. Determine the propeller efficiency

After calculating the value of thrust and torque, the last step is to calculate the efficiency value. In accordance with equation (4), then obtained the value of propeller efficiency to be displayed in a graphic.

From the results of data processing simulation results, then the data will be displayed in graphics as below

3) Data Calculation Graph

From the table of calculations on each model, the calculation results will then be made in graphical form. So that it can be concluded the characteristics of each model that has been simulated. The graphs include comparison of advance coefficients $(\mathrm{J})$ to thrust, torque and efficiency 


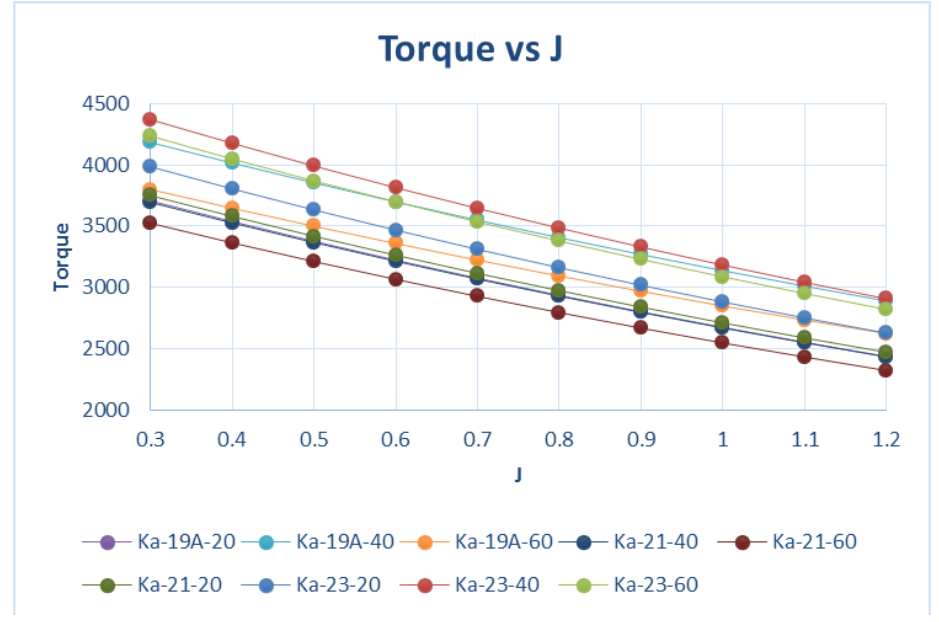

(a)

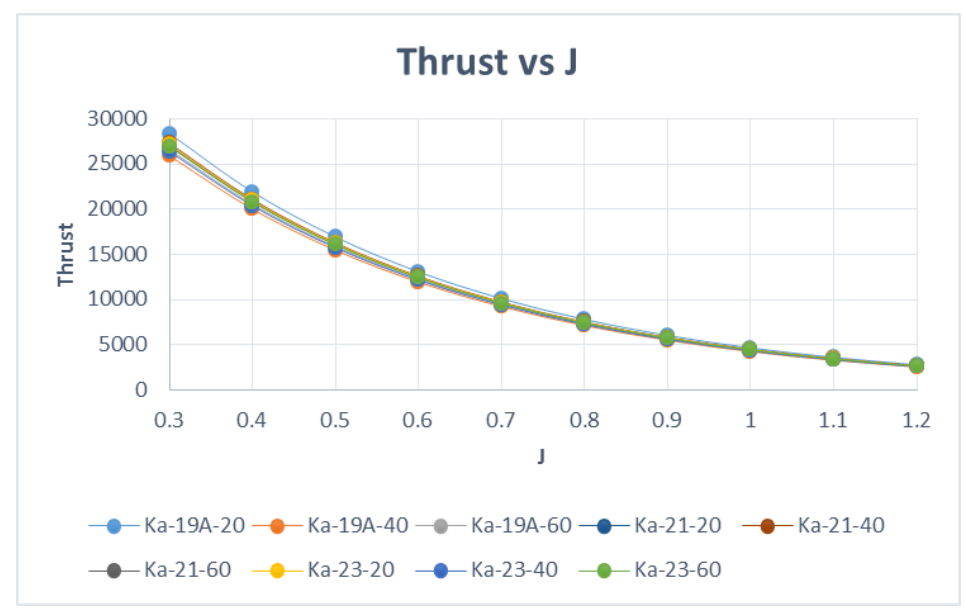

(b)

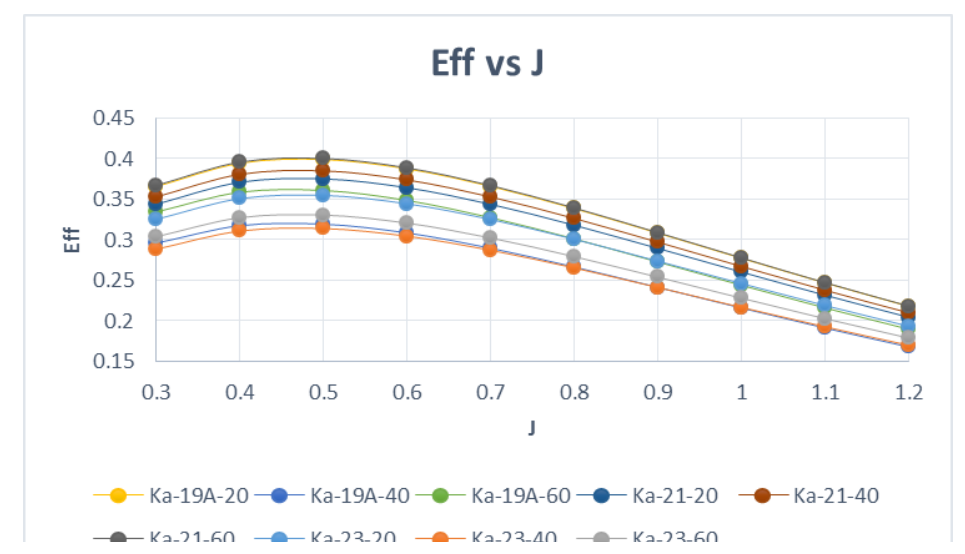

Figure. 4. Graph comparison of advance coefficient (J) with (a) torque, (b) thrust and (c) efficiency

In comparison graph of advance coefficient (J) to torque shows that the biggest value is Ka23-40 model with maximum torque value is $4,371 \mathrm{kNm}$ at $\mathrm{J} 0.3$. So the value of torque decreases with increasing coefficient advance (J), it can also be said that the value of torque decreases with decreasing propeller rotation, since the propeller rotation value is inversely proportional to the coefficient advance.

In the second graph, the comparison graph of the advance coefficient $(\mathrm{J})$ to the thrust, shows that the largest thrust value is in the Ka-19A-20 model with a thrust value of $28.362 \mathrm{kN}$ at $\mathrm{J} 0.3$. So the above graph can be concluded that the thrust or thrust force will decrease with the increasing value of advanced coefficient $(\mathrm{J})$. This is similar to the decrease in thrust force as the propeller rotation decreases, since the propeller rotation value is proportional to the advance coefficient $(\mathbf{J})$.

As for the comparison graph of advanced coefficient $(\mathrm{J})$ with propeller efficiency shows the highest efficiency of propeller is in Ka-2160 model with the value of propeller efficiency 
of 0.4 or $4.00 \%$ at $\mathrm{J} 0.5$. In contrast to the other graphs, the graph of the propeller efficiency relationship to the advance coefficient (J) means that the value of the propeller efficiency increases up to $\mathrm{J} 0.5$, then at $\mathrm{J} 0.6$ the efficiency value decreases with the coefficient advance
$(\mathrm{J})$.

The performance of propellers according to W. Adji [8] can be seen from the graph of performance, that is KQ KT J. In accordance with equations (1), (2) and (3) obtained KQ KT $\mathrm{J}$ graph as follows:

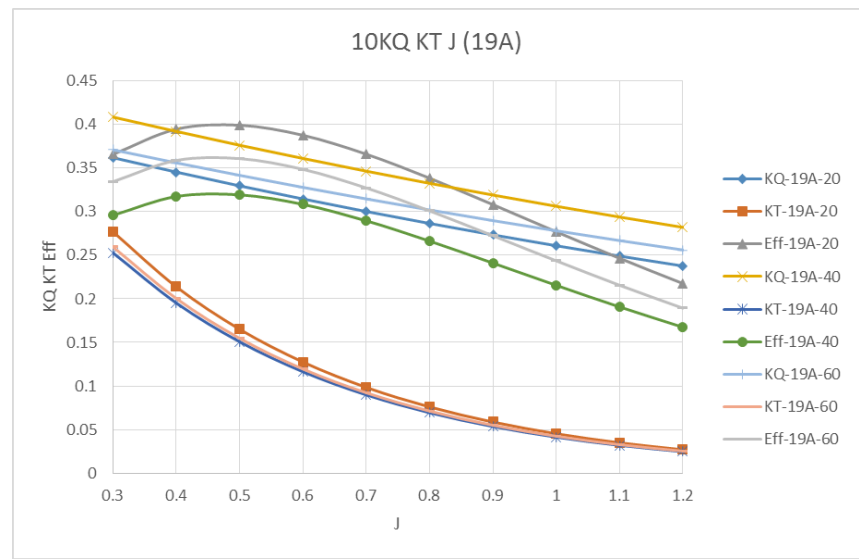

(a)

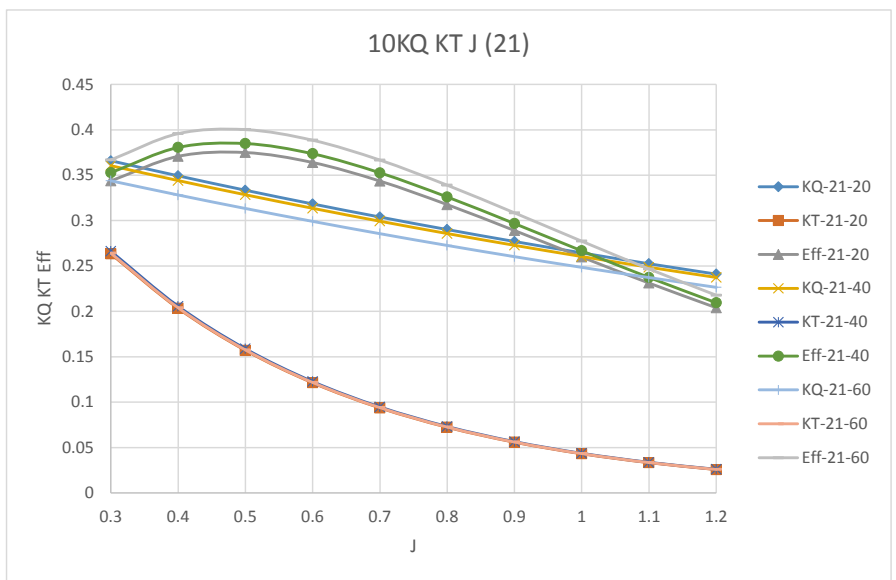

(b)

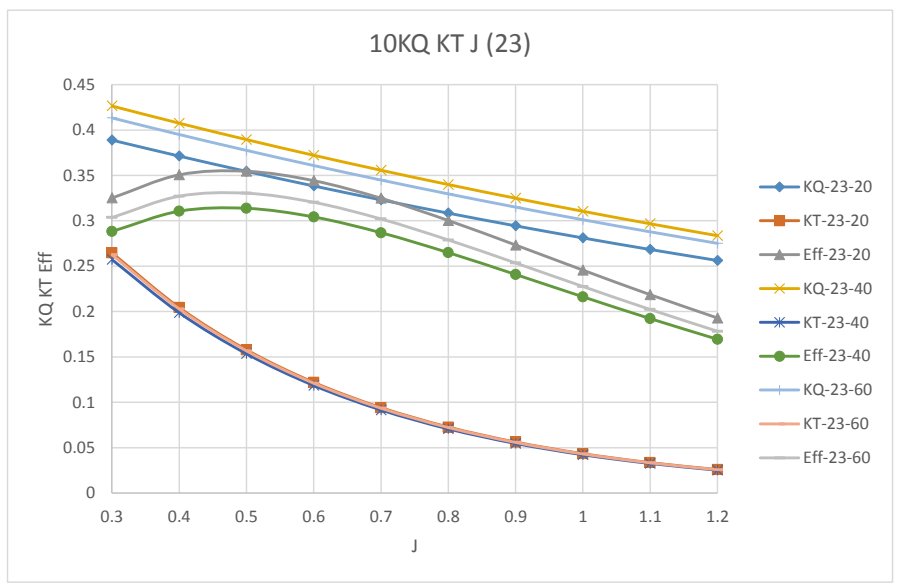

(c)

Figure. 5. KQ KT J chart on (a) Ka-19A, (b) Ka-21 dan (c) Ka-23 model

In addition presented in the form of tables and Figure 5, simulation results data are also presented in the form of images, the image is a contour and fluid flow in the model. Here is a pressure contour, flow velocity on the model: 
International Journal of Marine Engineering Innovation and Research, Vol. 2(1), Dec. 2017. 77-85 (pISSN: 2541 5972, eISSN: 2548-1479)

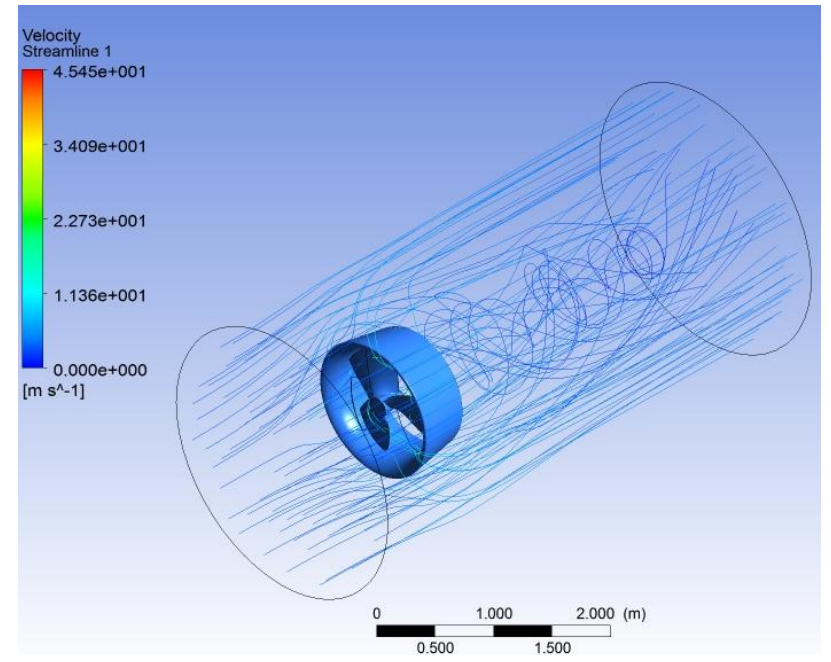

Figure. 6. Streamline fluid velocity on Ka-19A-60 model

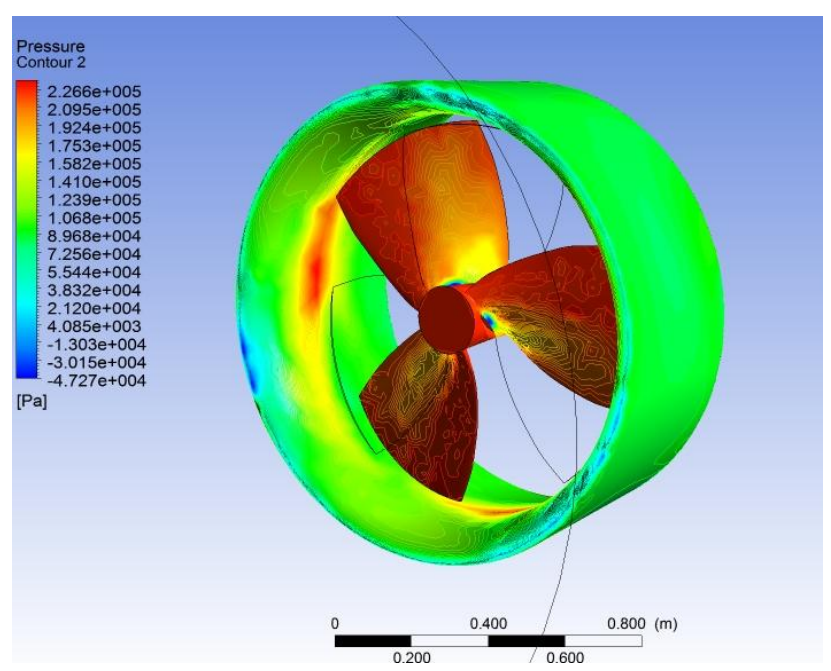

Figure. 7. Pressure contour on Ka-19A-60 model

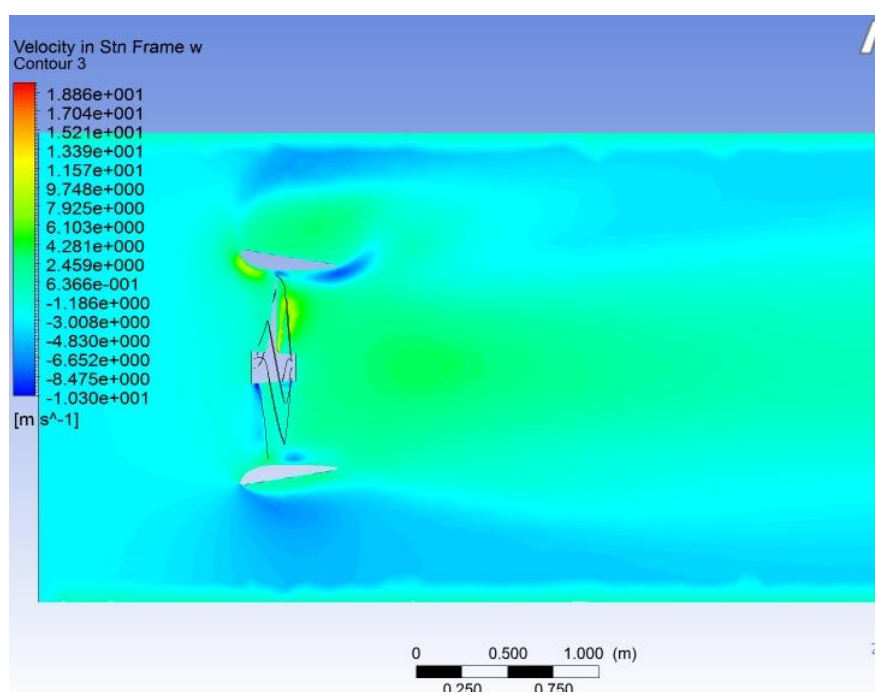

Figure. 8. Contour fluid velocity on Ka-19A-60 model 


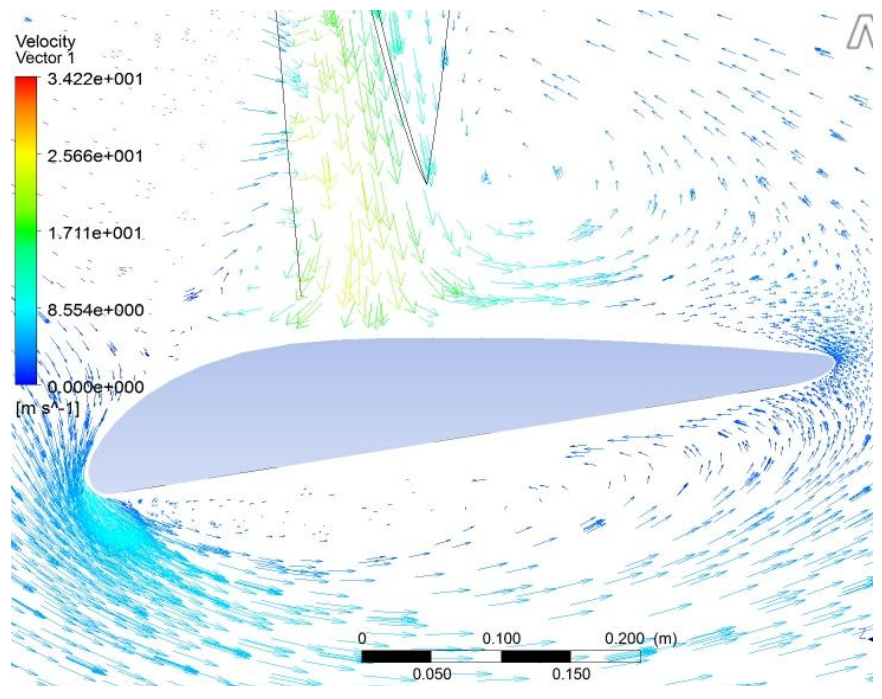

Figure. 9. Direction of the fluid flow vector in the duct on Ka-19A-60 model

In Figure 6. displayed streamline fluid flow on the fluid domain. From the figure it can be seen that the flow is rotating due to rotation of the propeller model and the focused flow in the middle due to the presence of the duct used in the propeller. While in the figure 7 . shows the pressure contours that occur in the propeller and duct. From the figure it can be seen that the higher pressure is on the leading edge propeller and also the inner part of the duct. This is due to the leading edge that hit the fluid first rather than the other propeller parts.

In Figure 8. shows the contours of fluid flow velocity. From the figure it can be seen that the fluid has a higher flow rate on the right duct than the left duct. This shows that the fluid flow increases as the flow passes through the rotating propeller, and the flow will be focused in the middle due to the duct, so thrust will increase. While in Figure 9. Shows the direction of flow vector flowing around the blade propeller and duct. From the figure it can be seen that the fluid flow that does not pass through the duct will move beyond the duct which will then coalesce at the end of the duct with the flow of fluid passing through the duct.

4) Validation Simulation

Validation should be made to the results of the analysis that has been done. This is done to ensure the resulting data has good accuracy. Validation of the most effective elements for the resulting data is valid, so that validation of the meshing element

Validation is also done on the results of the analysis by comparing the results of the analysis that has been done with the results of previous research. The results of that study will become a validation reference. So the results of the analysis should have a difference that is not too far or close to the results of analysis in previous studies. The result of previous research used is performance graph from $\mathrm{Ka}$ - series propeller with 19A nozzle duct from MARIN

Given the pressure and fluid velocity found on the face and back, which has the characteristics: low speed and high pressure on the face, as well as high speed and low pressure on the back. The difference in pressure between face and back is that there is a force lift. From the simulation results, the pressure on the face is greater than the pressure on the back. So from the results, it can be seen that the simulation results are in accordance with existing theory.

\section{CONCLUSION}

Based on the simulation results, data analysis and discussion has been done, it can be concluded that the greater Ld / D of the ducted propeller, the resulting thrust value will be lower, otherwise the torque value of the propeller will be higher. This is proved by the highest torque value found on Ka- 23-40 model with 4,371 kNm and the highest thrust value in Ka-19A-20 model with value $28.362 \mathrm{kN}$. While the best torque and thrust values are in the model with clearance tip of $40 \mathrm{~mm}$, in the model having $20 \mathrm{~mm}$ and $60 \mathrm{~mm}$ clearance tip the resulting torque and thrust value is lower than the model with $40 \mathrm{~mm}$ clearance tip. This is evidenced by the highest torque value found on the model Ka- 23-40 with a value of $43371 \mathrm{kNm}$, which is a model with a tip clearance $40 \mathrm{~mm}$.

\section{REFERENCES}

[1] Bontempo, R., Cardone, M. 2013. Ducted propeller flow analysis by means of a generalized actuator disk model. Energy Procedia. Volume 45 : 1107-1115

[2] Bontempo, R., Cardone, M. 2015. Performance analysis of ducter marine propeller :Part I - Decelerating duct. Applied Ocean Research. Volume $58: 332-330$

[3] Carlton, J. , "Marine Propeller and Propulsion Second Edition." Selsevier Ltd. USA, 2010.

[4] de Barros, E.A. ,Dantas, J.L.D. 2011. Effect of a propeller duct on AUV maneuverability. Ocean Engineering Journal. Volume $42: 61-70$

[5] Kuiper, G. "The Wageningen Propeller Series." MARIN Publication. Netherland, 1992. 
International Journal of Marine Engineering Innovation and Research, Vol. 2(1), Dec. 2017. 77-85 (pISSN: 2541 -

5972, eISSN: 2548-1479)

[6] Popov, E.P. "Mechanic of Materials.” San Francisco. Berkeley. 1984.

[7] Schneekluth, H., Bertram, V. 1998. Ship Design for Efficiency and Economy Second Edition. Butterworth Heinermann. Germany

[8] W. Adji, Suryo. "Engine Propeller Matching. Surabaya." Marine Engineering-ITS. 2005

[9] Yongle, D., Baowei, D. "Numerical investigation of tip clearance effects on the performance of ducted propeller". International
Journal Naval Architecture Ocean Engineering. Volume 7 : 795804, 2015.

[10] Santoso, Agoes et.al, "Flat Top Barge 300 feet Design using Portable Dynamics Positionning System". International Journal of Marine Engineering and Innovation Research, vol. 1 no. 2, pp. 106-113, March 2017. 